\title{
Development of a continuous process for $\alpha$-thio- $\beta$ - chloroacrylamide synthesis with enhanced control of a cascade transformation
}

\author{
Olga C. Dennehy ${ }^{1}$, Valérie M. Y. Cacheux ${ }^{1}$, Benjamin J. Deadman ${ }^{1} \S$, Denis Lynch¹, \\ Stuart G. Collins ${ }^{* 1}$, Humphrey A. Moynihan ${ }^{* 1}$ and Anita R. Maguire ${ }^{\star 2}$
}

\author{
Full Research Paper \\ Address: \\ ${ }^{1}$ Department of Chemistry, Analytical and Biological Chemistry \\ Research Facility, Synthesis and Solid State Pharmaceutical Centre, \\ University College Cork, Cork, Ireland and ${ }^{2}$ Department of Chemistry \\ and School of Pharmacy, Analytical and Biological Chemistry \\ Research Facility, Synthesis and Solid State Pharmaceutical Centre, \\ University College Cork, Cork, Ireland \\ Email: \\ Stuart G. Collins* - stuart.collins@ucc.ie; Humphrey A. Moynihan* - \\ H.Moynihan@ucc.ie; Anita R. Maguire* - a.maguire@ucc.ie \\ * Corresponding author \\ $\S$ Current address: Department of Chemistry, Imperial College \\ London, U.K. \\ Keywords: \\ $\alpha$-thio- $\beta$-chloroacrylamides; cascade reactions; flow chemistry
}

\author{
Beilstein J. Org. Chem. 2016, 12, 2511-2522. \\ doi:10.3762/bjoc. 12.246
}

Received: 22 September 2016

Accepted: 04 November 2016

Published: 24 November 2016

This article is part of the Thematic Series "Automated chemical synthesis".

Guest Editor: I. R. Baxendale

(C) 2016 Dennehy et al.; licensee Beilstein-Institut.

License and terms: see end of document.

\begin{abstract}
A continuous process strategy has been developed for the preparation of $\alpha$-thio- $\beta$-chloroacrylamides, a class of highly versatile synthetic intermediates. Flow platforms to generate the $\alpha$-chloroamide and $\alpha$-thioamide precursors were successfully adopted, progressing from the previously employed batch chemistry, and in both instances afford a readily scalable methodology. The implementation of the key $\alpha$-thio- $\beta$-chloroacrylamide casade as a continuous flow reaction on a multi-gram scale is described, while the tuneable nature of the cascade, facilitated by continuous processing, is highlighted by selective generation of established intermediates and byproducts.
\end{abstract}

\section{Introduction}

Since the efficient and highly stereoselective transformation of $\alpha$-thioamides to the corresponding $\alpha$-thio- $\beta$-chloroacrylamides derivatives was first reported [1,2], the considerable synthetic utility of these heavily functionalized acrylamide compounds has been well documented [3]. The predominant site of reactivity is at the electrophilic $\beta$-carbon, which results from the

combined influence of the amide and chloro substituents, mitigating the electron-donating effect of the sulfide moiety. Nucleophilic substitution [4], Diels-Alder reactions [5] and 1,3dipolar cycloadditions [6-9], and oxidation of the sulfide group [10-12] are among a wide array of transformations which have been successfully applied to these compounds (Scheme 1). 


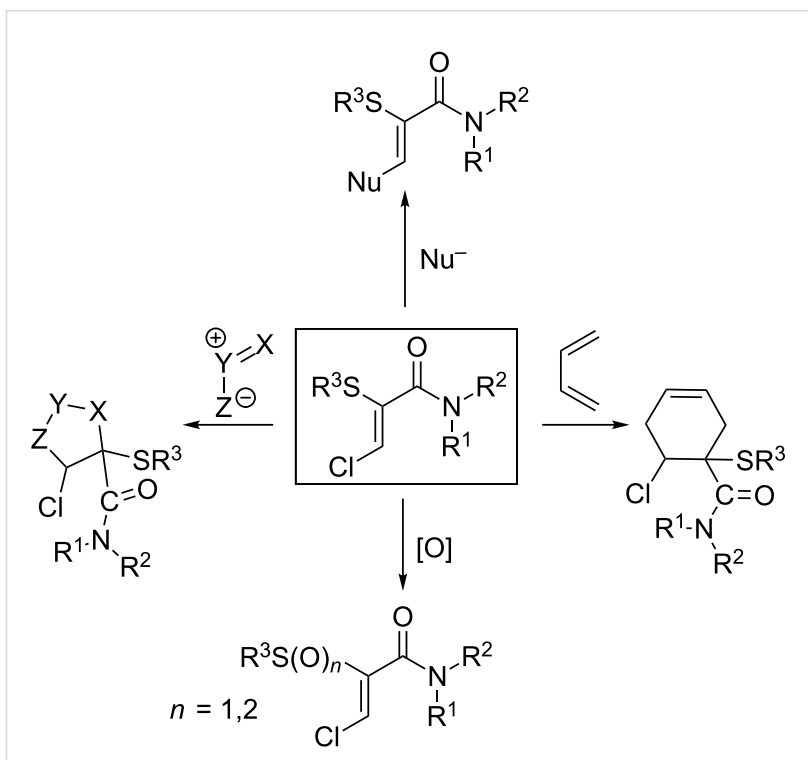

Scheme 1: Reaction pathways of $\alpha$-thio- $\beta$-chloroacrylamides.

In order to fully exploit the synthetic potential of these $\beta$-chloroacrylamides, however, a means of ready access to appreciable quantities of material is required. Preparation of $\alpha$-thio- $\beta$-chloroacrylamides typically results from a three-step synthetic route, culminating in a final cascade/domino reaction [13] where a toluene solution of $\alpha$-thioamide and NCS is subjected to a 'hot plunge' by placing it into an oil bath at $90{ }^{\circ} \mathrm{C}$ (Scheme 2). While this route has consistently provided a robust means of generating the desired $\beta$-chloroacrylamides at scales of $1-10 \mathrm{~g}$, it suffers from several disadvantages which impact on the ease of scale-up.

The preparation of the $\alpha$-chloroamide $\mathbf{1}$ is exothermic and requires significant external cooling, an undesirable feature for scale-up. The synthesis of the $\alpha$-thioamide $\mathbf{2}$ involves prior generation of fresh sodium ethoxide from sodium metal. Furthermore, this $\alpha$-thioamide protocol, at high $\mathrm{pH}$, ordinarily does not go to completion, leaving unreacted starting material and forming impurities which are subsequently removed by chro- matographic purification. Finally, the optimized conditions for the final cascade transformation employ rapid heating via 'hotplunge' in order to minimize the formation of process impurities during the initial heating phase [1]. This efficient rapid heating poses practical difficulties for scale-up and, furthermore, chromatographic separation is required to remove product impurities.

The nature of the aforementioned difficulties outlined are, however, largely specific to the scale-up of batch chemistry. A continuous processing approach frequently possesses advantages over the batch equivalent, as has been extensively documented [14-22]. When combined with automated operation, it allows for enhanced reproducibility and access to extreme conditions, which, along with improved heat and mass transfer, all facilitate significant ease of scale-up. The reaction control afforded by use of high surface-area-to-volume ratio tubular reactors, specifically with respect to dissipation of heat, offers a safety profile unique to flow chemistry. Continuous processing also provides the capacity to continuously generate hazardous reagents and intermediates in small quantities, in situ, and transferred directly into a reaction stage without operator handling [21-26]. As rapid heat transfer (steps 1 and 3) and greater reaction control (steps 2 and 3) were identified as the key challenges to be overcome, we envisaged that continuous processing could facilitate the preparation of large quantities of $\alpha$-thio$\beta$-chloroacrylamide with reduced purification requirements. The goal of this study was to develop an optimized process for the synthesis of $\alpha$-thio- $\beta$-chloroacrylamides, employing a model system with $N$-4'-methylphenyl-(Z)-3-chloro-2-(phenylthio)propenamide $(Z-3)$ as the target product. This optimized process would utilise flow chemistry as a key enabling technology to overcome the aforementioned challenges.

\section{Results and Discussion \\ Preparation of $\alpha$-chloroamide}

The synthesis of $\alpha$-chloroamide $\mathbf{1}$ is highly exothermic, due to the neutralisation of $\mathrm{HCl}$ - a byproduct - with triethylamine, and the need for effective heat removal imposes limitations on

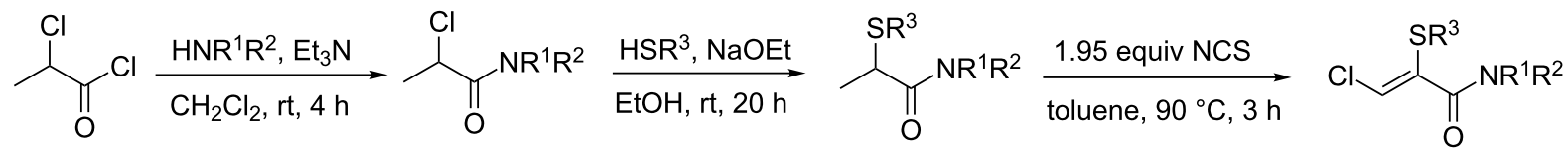

$$
\begin{aligned}
& \alpha \text {-chloroamide } \\
& \alpha \text {-thioamide } \\
& \alpha \text {-thio- } \beta \text {-chloroacrylamide } \\
& \left(R^{1} / R^{2}=\text { alkyl, aryl, } H\right) \\
& \text { ( } \mathrm{R}^{1 / \mathrm{R}^{2}}=\text { alkyl, aryl, } \mathrm{H} ; \mathrm{R}^{3}=\text { alkyl, aryl) } \\
& 2\left(R^{1}=H, R^{2}=\text { Tol, } R^{3}=P h\right) \\
& \left(R^{1} / R^{2}=\text { alkyl, aryl, } H\right. \text {; } \\
& \mathrm{R}^{3}=\text { alkyl, aryl) } \\
& \text { Z-3 }\left(R^{1}=H, R^{2}=\text { Tol, } R^{3}=P h\right)
\end{aligned}
$$


the batch scale-up of this step. It was envisaged that the efficient heat transfer properties of a high surface area tubular flow reactor would remove the need for external cooling of the reaction. To facilitate safe scale-up of this reaction we initially investigated a direct transfer of the batch process (Scheme 3 ) to continuous mode.

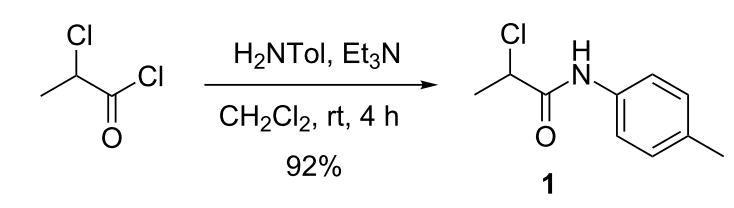

Scheme 3: Batch process for preparation of a-chloroamide 1.

Although initial investigations involving small throughput had shown promise, the practicalities of employing dichloromethane at process scales caused us to consider alternative 'greener' solvent systems [27]. A screen of alternative solvents in batch test reactions revealed that, while the amide formation was tolerant to most solvents, rapid precipitation of triethylamine hydrochloride would be problematic in a continuous process. Indeed, trial runs of a continuous process in ethyl acetate resulted in immediate blockage of the flow reactor at the point of reagent mixing. To prevent blockages due to salt formation we investigated replacements for triethylamine that would produce a more soluble $\mathrm{HCl}$ salt. Diisopropylethylamine (DIPEA) was found to be a suitable base that allowed the continuous process to be carried out in ethyl acetate without any observed precipitation of the $\mathrm{HCl}$ salt. The 'greener' continuous amide formation (Scheme 4) was carried out on a large scale, producing $91 \mathrm{~g}$ (92\% yield) of the $\alpha$-chloroamide $\mathbf{1}$ over 5 hours of continuous operation, as a white crystalline solid after aqueous work-up and recrystallization.

\section{Synthesis of a-thioamide}

Driving the reaction to completion and avoiding the use of sodium metal were the key aims in transferring $\alpha$-thioamide preparation from batch to flow. Although yields of $80-90 \%$ can be obtained under batch conditions, incomplete conversion to $\alpha$-thioamide 2 necessitates a difficult, and often laborious, chromatographic separation, as starting material $\mathbf{1}$ and product $\mathbf{2}$ are poorly resolved. Indeed, high-purity batches of $\alpha$-thioamide 2 are often not achieved by chromatography, with the resulting product typically ca. $94 \%$ pure by HPLC. It was also envisaged that the facility to superheat the solvent in a pressurised continuous platform could enable sodium ethoxide to be replaced by a weaker base, obviating the need for sodium metal.

At an early stage of process development, the possibility of telescoping the amide formation and thiolation steps was consid-

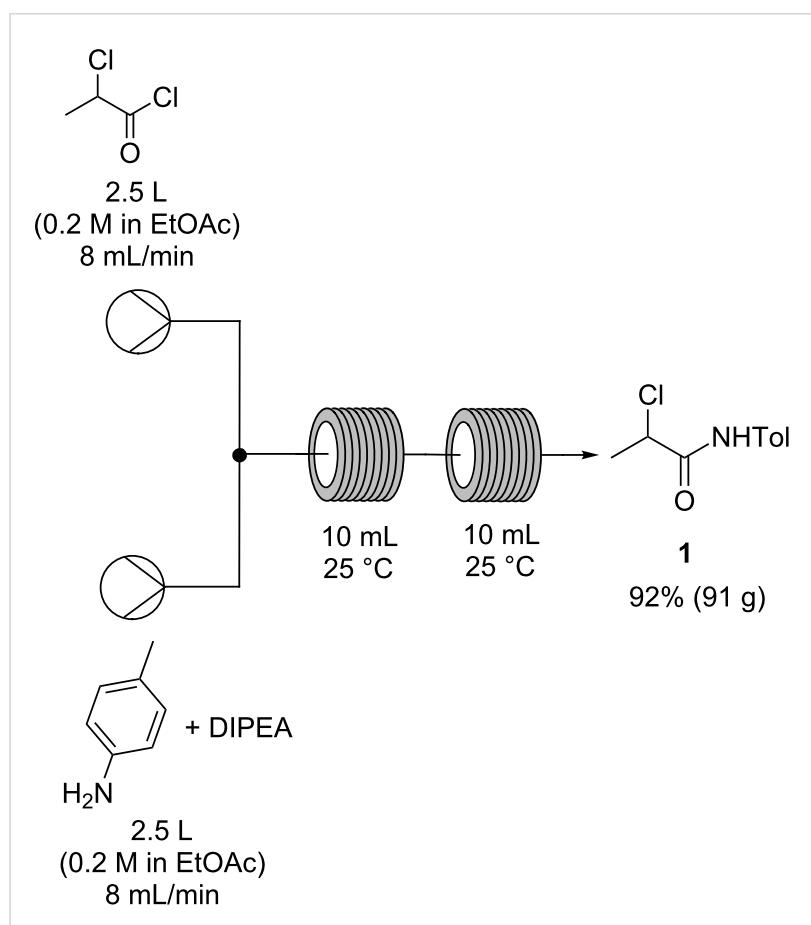

Scheme 4: Process for the conversion of 2-chloropropionyl chloride and $p$-toluidine to $\alpha$-chloroamide 1 under optimized flow conditions.

ered. Attempts were made to use triethylamine as the base in a continuous thiolation reaction, however, the reaction was found to progress slowly and a maximum conversion of $39 \%$ was observed by ${ }^{1} \mathrm{H}$ NMR spectroscopy. Elevating the temperature to $90{ }^{\circ} \mathrm{C}$ and employing DBU, as a more basic alternative to triethylamine, did not increase the reactivity. Hence, the focus was instead directed on converting the existing batch process (Scheme 2), with sodium ethoxide as base, into a stand-alone continuous process.

Initially, however, the sodium chloride byproduct was found to precipitate from ethanol causing blockages at the back-pressure regulator. As sodium chloride possesses a relatively low solubility in ethanol (ca. $0.055 \mathrm{~g}$ in $100 \mathrm{~g}$ of ethanol at $20^{\circ} \mathrm{C}$ ) compared to methanol (1.375 g in $100 \mathrm{~g}$ ) [28], methanol was proposed as an alternative solvent. As ${ }^{1} \mathrm{H}$ NMR analysis indicated that the crude reaction product from batch tests (using methanol as solvent) consisted of $98 \% \alpha$-thioamide 2 , the process was subsequently transferred to a continuous flow system (Scheme 5).

A variety of temperatures $\left(60-120^{\circ} \mathrm{C}\right)$, bases $(\mathrm{NaOMe}, \mathrm{NaOH}$, $\left.\mathrm{Na}_{2} \mathrm{CO}_{3}\right)$ and concentrations $(0.1-0.3 \mathrm{M})$ were investigated using methanol as solvent (see Supporting Information File 1), however, unreacted $\alpha$-chloroamide 1 and diphenyl disulfide were detected as product components in all experiments. Direct sampling of the reaction mixture (system effluents) also showed 


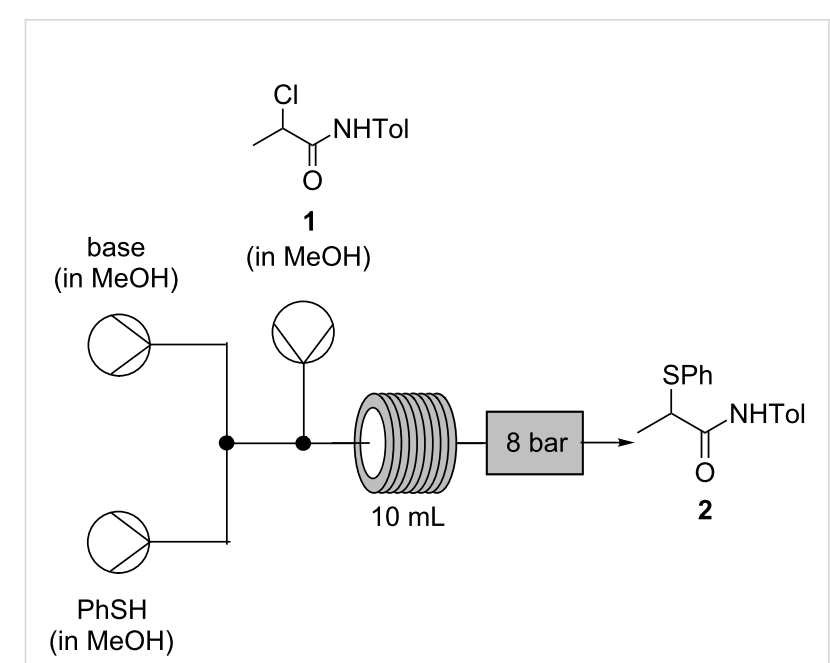

Scheme 5: Conversion of $\mathbf{1}$ to $\mathbf{2}$ in continuous mode using $\mathrm{MeOH}$ as solvent.

additional component peaks by HPLC analysis, which were not observed in material isolated after the reaction work-up. While temperatures above $100{ }^{\circ} \mathrm{C}$ or $\alpha$-chloroamide 1 concentrations above $0.1 \mathrm{M}$ were not found to be advantageous, sodium hydroxide demonstrated promising results when used as base.

With use of sodium hydroxide in mind, replacement of methanol with an ethanol/water mixture as solvent was subsequently examined. This solvent change was investigated in conjunction with further refinements to the stoichiometry of sodium hydroxide and thiophenol used, along with optimization of process temperature and residence time (Table 1).

Initially, when using 10 equivalents of sodium hydroxide, the best conversion to product 2 was obtained at a reaction temperature of $120{ }^{\circ} \mathrm{C}$ (entry 2, Table 1), with no unreacted $\alpha$-chloroamide 1 detected by HPLC. Employing just 5 equivalents of hydroxide also provided an acceptable yield of $\alpha$-thioamide 2 in all instances (entries 4-13, Table 1). The use of an excess of sodium hydroxide as base had removed the difficulty with unreacted starting material, presumably by hydrolysis of unreacted $\alpha$-chloroamide $\mathbf{1}$ to more water soluble byproducts. In order to minimize the presence of diphenyl disulfide in the isolated product, the stoichiometry of thiophenol was also examined. Interestingly, a reduction in the excess of thiophenol to 1.05 equivalents was found to give a greater proportion of $\alpha$-thioamide 2 and significantly reduced level of diphenyl disulfide (entries 7-13, Table 1).

After an improved stoichiometry of reagents had been established, lowering the residence time was investigated to facilitate efficient large scale synthesis by a continuous flow process.
Ultimately, a residence time of $5 \mathrm{~min}$ at $120^{\circ} \mathrm{C}$, using a $0.25 \mathrm{M}$ concentration of $\alpha$-chloroacrylamide, was found to give an acceptable quality of product 2 , with no detectable quantities of starting material $\mathbf{1}$ or diphenyl disulfide by HPLC analysis (entry 13, Table 1).

The optimized continuous process (Scheme 6) was then run on a $5 \mathrm{~g}$ scale with no observed loss of yield or purity. The $\alpha$-thioamide 2 , which crystallized directly from the output of the flow process, was obtained in $71 \%$ yield and found to be $>99 \%$ pure by HPLC analysis, compared to $94 \%$ purity for a typical batch preparation following chromatography.

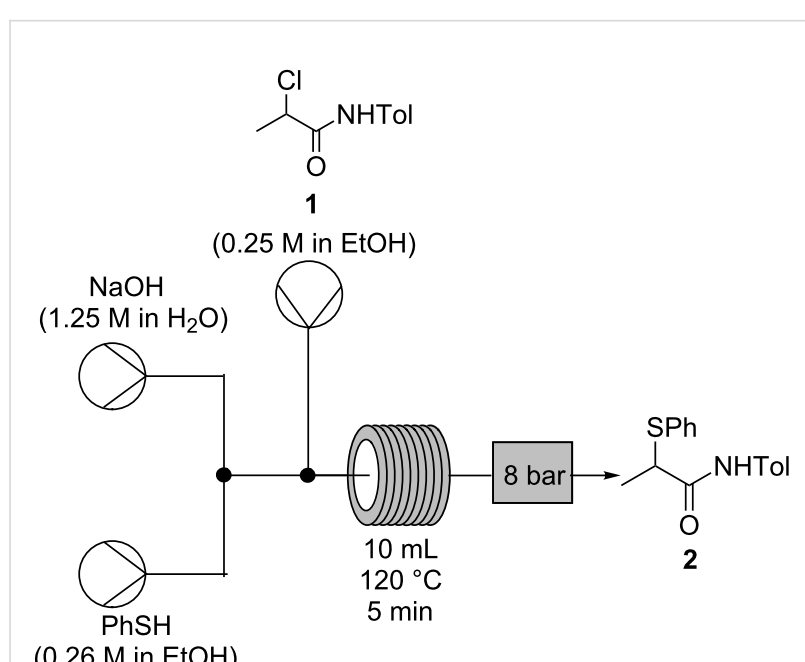

Scheme 6: Optimized process for the conversion of $\alpha$-chloroamide 1 to $\alpha$-thioamide 2 under flow conditions.

As transferring the $\alpha$-thioamide preparation to a continuous platform had involved a number of important changes to the reaction conditions, it was decided to evaluate the optimized flow conditions (entry 13, Table 1) when applied to a batch process for comparison: 1.05 equivalents of thiophenol in ethanol mixed with an aqueous solution containing 5 equivalents of sodium hydroxide followed by heating to reflux for 1 hour. Initially on a $500 \mathrm{mg}$ scale, a $97 \%$ yield of $\alpha$-thioamide 2 was obtained, while operating at a higher concentration (increased from $0.25 \mathrm{M} \alpha$-chloroamide 1 to $0.4 \mathrm{M} \alpha$-chloroamide 1) a yield of $94 \%$ was achieved on a $5 \mathrm{~g}$ scale, with the isolated product determined to be $99 \%$ pure by HPLC analysis. This process was ultimately carried out at a $20 \mathrm{~g}$ scale achieving $88 \%$ yield, again with $99 \%$ purity; the decrease in yield was offset by the increase in both productivity at this scale and product purity. The ability to operate effectively at higher concentrations in batch than in flow, in this case, made this batch process the optimum method of $\alpha$-thioamide preparation, with a considerable reduction in reaction time from 10 hours to just 1 hour 
Table 1: Optimization of temperature, thiophenol concentration, residence time and stoichiometry of base for conversion of $\mathbf{1}$ to $\mathbf{2}$ in continuous mode ${ }^{a}$ using $\mathrm{EtOH} / \mathrm{H}_{2} \mathrm{O}$ as solvent.

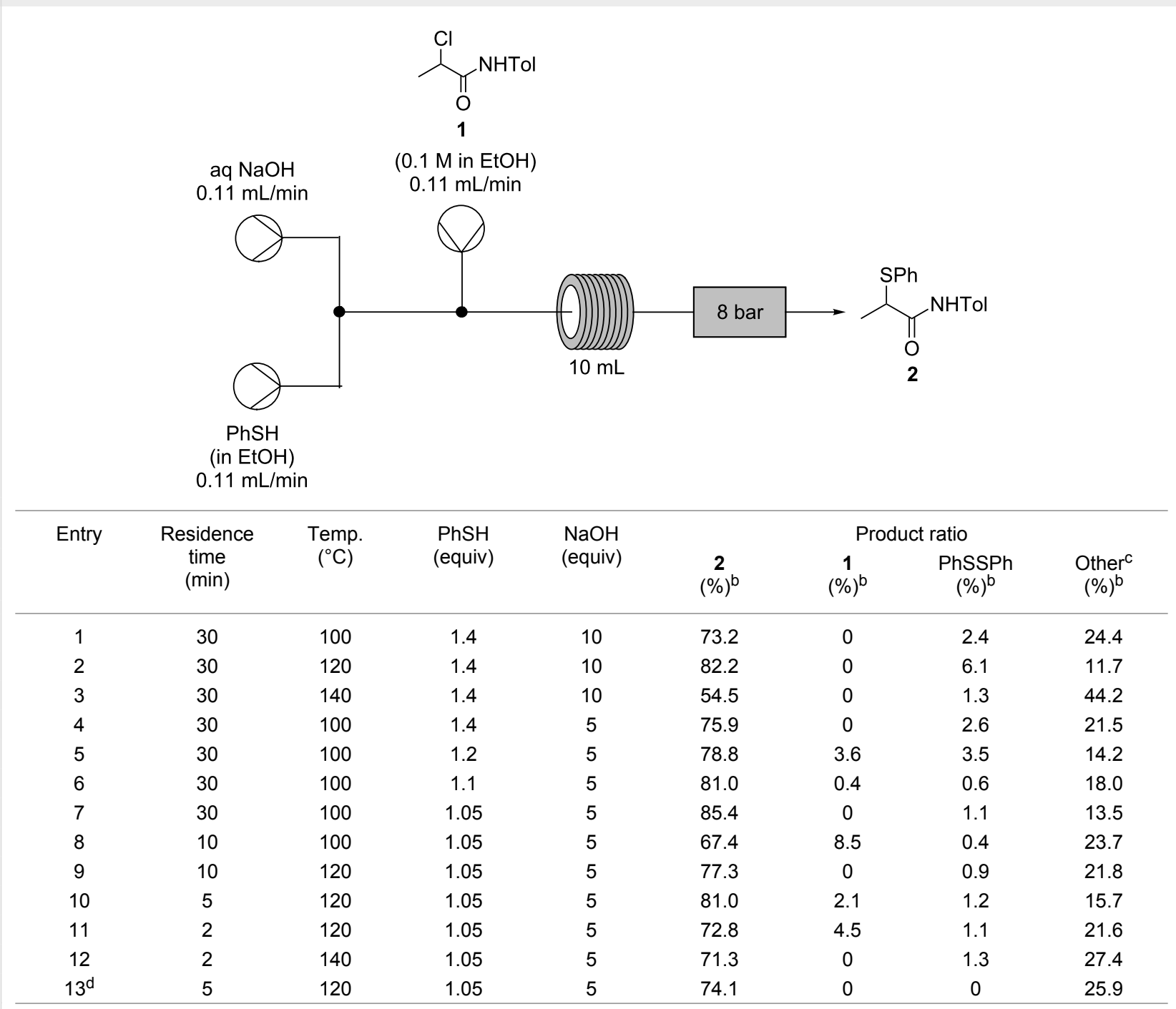

aGeneral conditions: 1 equiv a-chloroamide 1 ( $2 \mathrm{~mL}$ of a $0.1 \mathrm{M}$ solution in $\mathrm{EtOH}$ ) was reacted with $\mathrm{PhSH}$ (as a solution in $\mathrm{EtOH})$ and $\mathrm{NaOH}$ (as a solution in $\mathrm{H}_{2} \mathrm{O}$ ). ${ }^{b}$ Determined by HPLC analysis (peak area: see Supporting Information File 1) of samples taken directly from flow reactor as effluent solutions and diluted in MeCN prior to analysis. 'Unisolated components, not present after work-up. ${ }^{\mathrm{d}}$ Reaction was run using $2 \mathrm{~mL} 0.25 \mathrm{M}$ solution of a-chloroamide 1 in EtOH.

(for $20 \mathrm{~g}$ of 2 ) and with a reduction of approximately one third in the required solvent volume, compared to the flow process. By comparison, the original batch process was typically run for 20 hours on scales up to $10 \mathrm{~g}$.

As with the optimized flow process, direct crystallisation of the $\alpha$-thioamide product 2 from this improved batch process was achieved by cooling and adding water as anti-solvent. This method of product isolation obviated the need for the arduous work-up - involving extraction into dichloromethane and several aqueous washes - associated with the original batch version, and gave material which was $99 \%$ purity or greater by HPLC analysis.
The stoichiometry of sodium hydroxide required for reaction completion was also considered as part of the batch comparison. Here, a reduction from 5 equivalents to 3 and subsequently to just 2 equivalents was found to be possible, with no discernible negative impact on the product formation. In the latter case, in batch the $\alpha$-thioamide 2 was recovered in $92 \%$ yield and $>99 \%$ purity by HPLC, when the reaction was performed on a $5 \mathrm{~g}$ scale. A subsequent batch run on a $20 \mathrm{~g}$ afforded an $89 \%$ yield, with the same level of product purity. It is, perhaps, worth noting that the high isolated yields obtained from the scaled-up reactions strongly suggest that the substantial quantities of 'other' components observed by HPLC analysis, but removed during work-up, are overestimated by detection at $250 \mathrm{~nm}$ 
(Table 1). Such an overestimation is consistent with the presence of additional chromophores, when compared to the desired product, and would indicate that these observed components may contain an $\alpha, \beta$-unsaturated carbonyl motif in their structures.

The value of exploring flow methodology, ultimately leading to an improved batch process, is keenly highlighted in this instance. The optimized batch process, developed through examining the use of continuous processing, can produce $20 \mathrm{~g}$ of pure material, with direct product precipitation/crystallization from the reaction solution ( $>99 \%$ pure by HPLC analysis), which has removed the requirements for isolation by extraction and subsequent chromatographic purification. HPLC analysis of the current process - in either batch or flow - indicated complete consumption of the $\alpha$-chloroamide 1 , without diphenyl disulfide formation, while an increase in yield from $80-90 \%$ to consistently over $90 \%$ has been achieved. Furthermore, the use of an inert atmosphere is no longer necessary as the decrease in reaction time has essentially eliminated the opportunity for aerobic oxidation of the thiophenolate anion to diphenyl disulfide, while sodium metal is no longer used as part of the process.

\section{$\alpha$-Thio- $\beta$-chloroacrylamide cascade in flow}

Successful conversion of the $\beta$-chloroacrylamide cascade step from batch to flow posed a number of challenges. The reaction mechanism (Scheme 7) involves a complex cascade which also

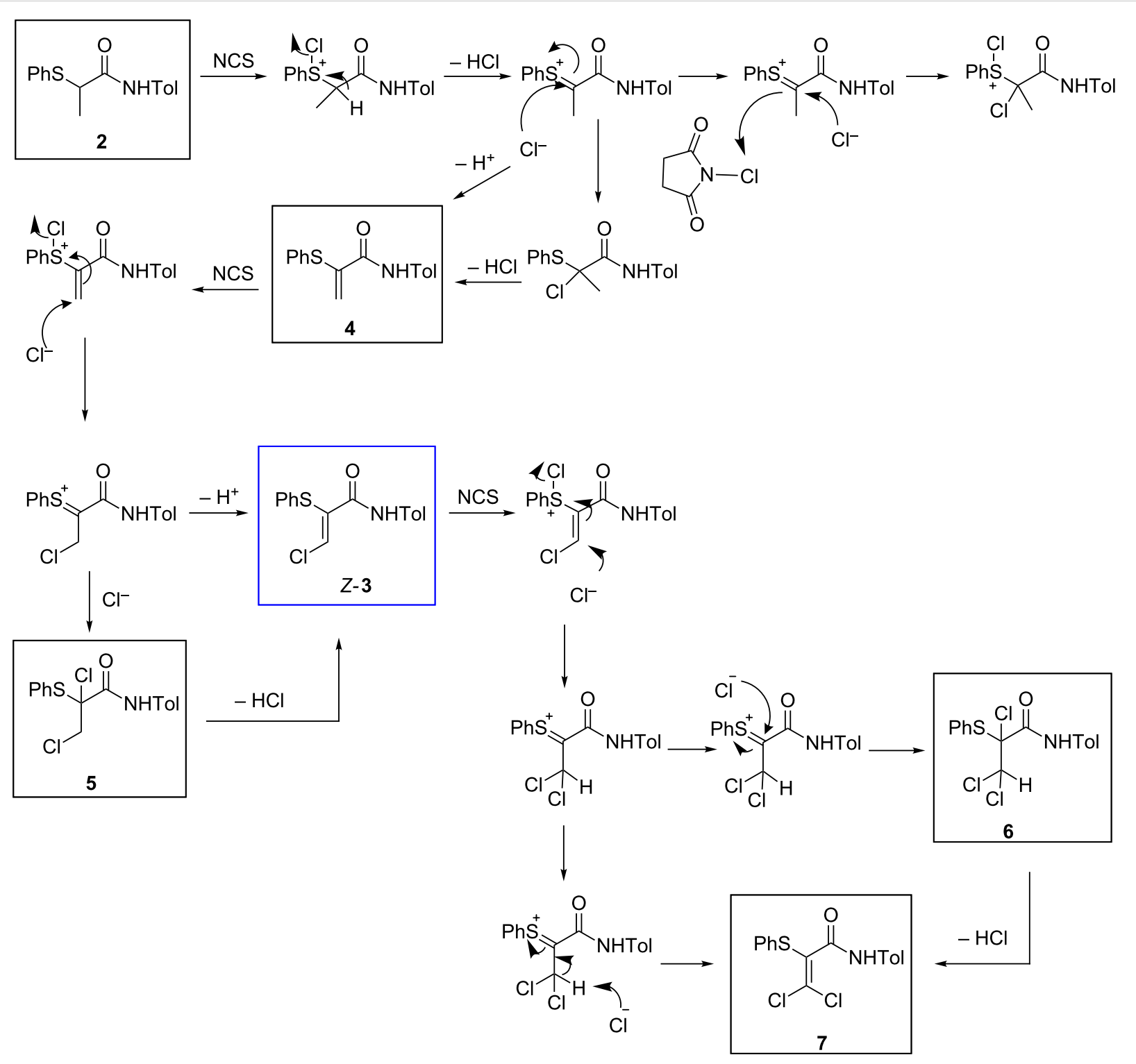


gives rise to several known impurities, including acrylamide 4 , dichloride 5, trichloride 6 and dichloroacrylamide 7.

In the optimized batch synthesis of $\alpha$-thio- $\beta$-chloroacrylamide $Z$-3 from the corresponding $\alpha$-thioamide $2, N$-chlorosuccinimide (NCS) is added in one portion to a solution of $\mathbf{2}$ in toluene and the reaction mixture is immediately immersed in an oil bath at $90{ }^{\circ} \mathrm{C}$ (Scheme 2). Although this protocol performs well, giving $91 \%$ yield on a ca. $5 \mathrm{~g}$ scale [1], the practical challenges of achieving efficient rapid heating on a larger scale in batch made continuous processing an attractive alternative for scaleup due to its capacity for excellent temperature control. Efficient heat transfer due to the high surface, low volume geometry of tubular flow reactors makes it possible to achieve extremely rapid temperature transitions. It was envisaged that flowing the reaction through a heated section of tubing would be analogous to the batch 'hot plunge' method but with the capacity for faster heating of the reaction.

Given the superior performance of $\alpha$-thioamide 2 synthesis in batch, the potential telescoping of the thiolation process with the $\beta$-chloroacrylamide cascade was not investigated. Furthermore, the potential vulnerability of $\alpha$-thio- $\beta$-chloroacrylamides towards nucleophilic substitution by an aqueous ethanol compo- nent of the reactant stream (from $\alpha$-thioamide 2 preparation), particularly at elevated temperatures, strongly mitigated against integrating these steps.

For the batch process, the solubility of NCS in toluene has notable benefits: NCS is soluble in toluene at high temperatures, while the succinimide byproduct readily precipitates from toluene on cooling, allowing its convenient removal by filtration. In a continuous flow process, however, succinimide precipitation would cause blockage of the system.

Attempts at transferring the cascade reaction to a continuous platform began with direct adaptation of the existing batch process (Table 2). The solubility of NCS in toluene was found to be variable and often unsuitably low. Only batches of NCS which readily gave complete solutions were used and these batches were always either freshly recrystallized or commercial batches which were 'newly' opened prior to use. The reduced solubility of other batches was attributed to the partial hydrolysis of NCS upon intermittent exposure to ambient conditions over prolonged periods, also generating $\mathrm{HCl}$.

Initial investigations using our prototype flow process employed $0.01 \mathrm{M}$ solutions of NCS and starting material 2 in tolu-

Table 2: Initial flow process for conversion of $\mathbf{2}$ to Z-3 using toluene as solvent.

\begin{tabular}{|c|c|c|c|c|c|c|}
\hline $\begin{array}{r}(0.01 \\
(0.01 \mathrm{M}\end{array}$ & nol & $\begin{array}{l}10 \mathrm{~mL} \\
120^{\circ} \mathrm{C}\end{array}$ & 7 bar & $\mathrm{SF}$ & & \\
\hline Entry & $\begin{array}{c}\text { Ratio } \\
\text { 2:NCS }\end{array}$ & $\begin{array}{l}\text { Residence Time } \\
\text { (min) }\end{array}$ & $\begin{array}{c}2 \\
(\%)^{b}\end{array}$ & $\begin{array}{c}4 \\
(\%)^{b}\end{array}$ & 5 & $\begin{array}{l}Z-3 \\
(\%)^{b}\end{array}$ \\
\hline 1 & $1: 2$ & 20 & 19 & 15 & 18 & 47 \\
\hline 2 & $1: 2$ & 50 & 21 & 19 & 0 & 60 \\
\hline 3 & $1: 2.3$ & 20 & 22 & 8 & 20 & 46 \\
\hline 4 & $1: 3$ & 20 & 25 & 1 & 12 & 62 \\
\hline 5 & $1: 1$ & 20 & 21 & 77 & $<1$ & 2 \\
\hline
\end{tabular}

astoichiometric ratio of $\alpha$-thioamide 2:NCS controlled by manipulating the relative flow rates. ${ }^{b}$ Molar ratio determined by HPLC analysis (peak area weighted for relative response factors of each component: see Supporting Information File 1) of samples taken directly from flow reactor as effluent solutions and diluted in MeCN prior to analysis. 
ene. The equivalent of a 'hot-plunge' method was achieved by passing the reaction solution through a coiled tube reactor at $120^{\circ} \mathrm{C}$. The high surface area-volume ratio of tubular flow reactors is ideal for such rapid temperature transitions. It was noted that a relatively short residence time of only $20 \mathrm{~min}$ could be used, with a longer time of 50 min offering only a modest improvement on the reaction outcome (entries 1 and 2, Table 2). Indeed, the conversion of starting material $\mathbf{2}$ to acrylamide $\mathbf{4}$ was found to be closely comparable, indicating almost identical reaction progress, given the instability of dichloride $\mathbf{5}$, which easily converts to the final product $Z-\mathbf{3}$.

Increasing the amounts of NCS used was found to lead to a better conversion of acrylamide 4 to dichloride 5 or $\alpha$-thio- $\beta$ chloroacrylamide $Z-3$ (entries 3 and 4, Table 2), with only $1 \%$ of acrylamide 4 left unreacted with three equivalents of NCS used. When only an exact stoichiometric ratio $(1: 1)$ of NCS was used, the reaction stopped after the first chlorination step, leading to a reaction mixture which contained acrylamide $\mathbf{4}$ as the main product formed (entry 5 , Table 2). This ability to halt the cascade at the acrylamide intermediate 4 or push through to the $\alpha$-thio- $\beta$-chloroacrylamide $Z$-3 highlights the enhanced control of reaction stoichiometry afforded by a continuous platform and offers the possibility to isolate selected intermediates in the cascade reaction using a continuous process, more effectively than in batch and with greater flexibility.

\section{Optimization of the cascade process using flow chemistry}

In all the aforementioned cases (Table 2), around $20 \%$ of the starting material was consistently found to be unreacted. The key limitation to overcome was proposed to be the low solubility of NCS in toluene, and the consequent limitations to reactor throughput. To offset this difficulty, the use of alternative solvents was investigated. Acetonitrile was considered as a possible alternative solvent due to the high solubility of NCS it offers. Hence, preliminary experiments were carried out in order to compare its performance to toluene (Table 3), with the $\alpha$-thioamide 2 :NCS ratio again adjusted by manipulating the concentration of the reagent solutions. In these experiments, the reaction conversions were determined using ${ }^{1} \mathrm{H}$ NMR analysis of the crude product material obtained, with characteristic proton signals of the $\beta$-carbon of the starting material $\mathbf{2}$, intermediates $\mathbf{4}$ and $\mathbf{5}$, and the desired product $Z-\mathbf{3}$ being easily identifiable.

Using toluene as a solvent for both reagents ( $\alpha$-thioamide $\mathbf{2}$ and NCS) leads to $10 \%$ unreacted acrylamide 4 (entry 1 , Table 3 ).

Table 3: Solvent screen for conversion of $\mathbf{2}$ to $Z-3$ in continuous mode.

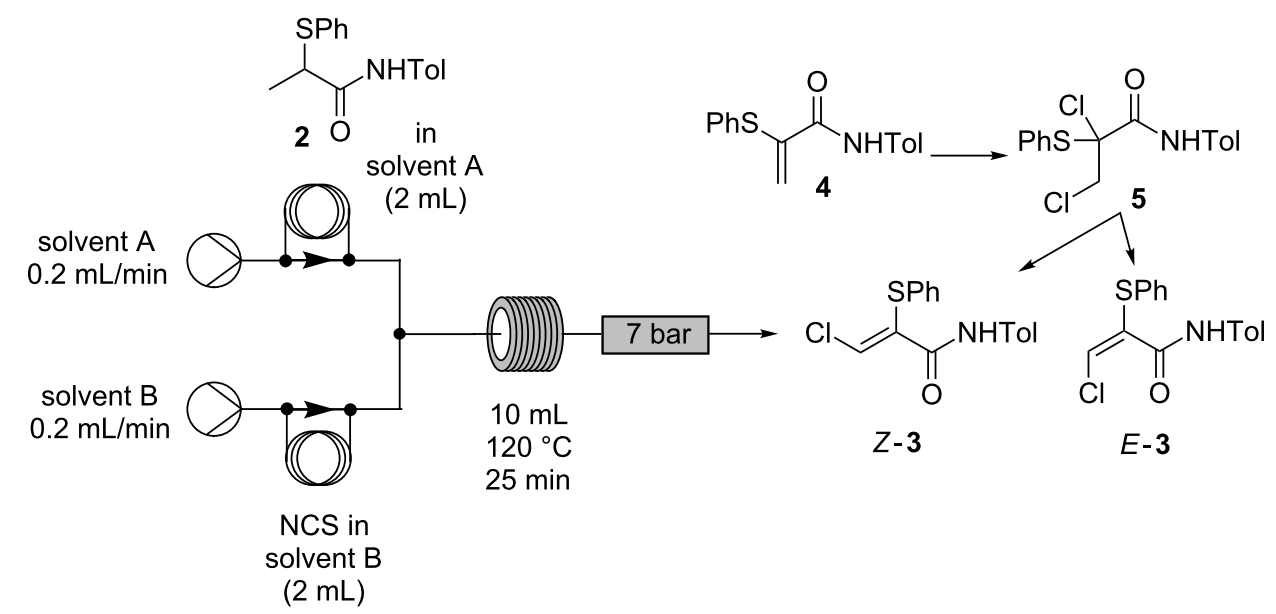

\begin{tabular}{|c|c|c|c|c|c|c|c|c|}
\hline \multirow[t]{2}{*}{ Entry } & \multirow{2}{*}{$\begin{array}{c}\text { [a-Thioamide 2] } \\
(\mathrm{mM})\end{array}$} & \multirow{2}{*}{$\begin{array}{c}{[\mathrm{NCS}]} \\
(\mathrm{mM})\end{array}$} & \multirow{2}{*}{$\begin{array}{l}\text { Solvent } \\
\text { A/B }\end{array}$} & \multicolumn{5}{|c|}{ Product ratio } \\
\hline & & & & $\begin{array}{c}2 \\
(\%)^{a}\end{array}$ & $\begin{array}{c}4 \\
(\%)^{a}\end{array}$ & $\begin{array}{c}5 \\
(\%)^{a}\end{array}$ & $\begin{array}{c}Z-3 \\
(\%)^{a}\end{array}$ & $\begin{array}{l}E-3 \\
(\%)^{\mathrm{a}}\end{array}$ \\
\hline 1 & 25 & 50 & Tol/Tol & 0 & 9.9 & 9.9 & 78.7 & 1.5 \\
\hline 2 & 25 & 50 & Tol/MeCN & 0 & 4.3 & 0 & 81.4 & 14.3 \\
\hline 3 & 25 & 50 & $\mathrm{MeCN} / \mathrm{MeCN}$ & 0 & 0 & 0 & 86.9 & 13.1 \\
\hline 4 & 200 & 400 & Tol/MeCN & 0 & 7.3 & 0 & 83.5 & 9.2 \\
\hline 5 & 200 & 400 & $\mathrm{MeCN} / \mathrm{MeCN}$ & 0 & 0 & 0 & 87.8 & 12.2 \\
\hline
\end{tabular}

aDetermined by ${ }^{1} \mathrm{H}$ NMR spectroscopy. 
When a solution of $\mathbf{2}$ in toluene and a solution of NCS in acetonitrile were employed as the reactant streams, similar results were observed at either low or high concentration, in terms of residual acrylamide intermediate detected (entries 2 and 4 , Table 3). However when acetonitrile was used as solvent for both reagents ( $\alpha$-thioamide 2 and NCS), full conversion to the final product Z-3 was observed, at both high and low concentration of reagents (entries 3 and 5, Table 3 ). Use of high concentrations has the advantage of increasing process productivity. In this case (entry 5 , Table 3 ), the production could be increased eight-fold for the same reaction time as entry 3 (25 min residence time). Furthermore, higher concentration of reagents enables greener synthesis by reducing solvent use.

Interestingly, during development studies on the conversion of $\alpha$-thioamide 2 to $\alpha$-thio- $\beta$-chloroacrylamide Z-3 in acetonitrile, by flow or in batch, a new component of the cascade reaction was observed, which was identified as the $(E)$ - $\alpha$-thio- $\beta$ chloroacrylamide $E$-3.

An important feature of the experiments conducted on the $\beta$-chloroacrylamide cascade as a continuous process was the complete absence of the over-chlorinated products $\mathbf{6}$ and $\mathbf{7}$, which were not observed by HPLC analysis or ${ }^{1} \mathrm{H}$ NMR spectroscopy. In contrast, when similar conditions were employed in batch, significant formation of these byproducts was often in evidence [1]. The flow process for the conversion of $\alpha$-thioamide 2 to $\alpha$-thio- $\beta$-chloroacrylamide 3 which employed acetonitrile as solvent was therefore taken forward for optimization and scale-up (Table 4).

The residence time of the flow process was investigated to determine the completion time of the reaction, principally to minimize the extent of impurity formation due to over-reaction. The shortest possible effective residence time would be also preferable for larger scale operation in order to maximize the reactor throughput. The dichloride intermediate $\mathbf{5}$ was still present after a 2 min residence time (entry 5, Table 4), implying the reaction had not yet reached completion, while minor impurities remained at similar levels throughout all of the experiments. The succinimide byproduct was removed in the product work-up.

At lower reaction temperatures, large quantities of the dichloride 5 were observed (entries 6-8, Table 4), with correspond-

Table 4: Optimization of flow rates, residence time and temperature for conversion of 2 to Z-3 in continuous mode ${ }^{\mathrm{a}}$.
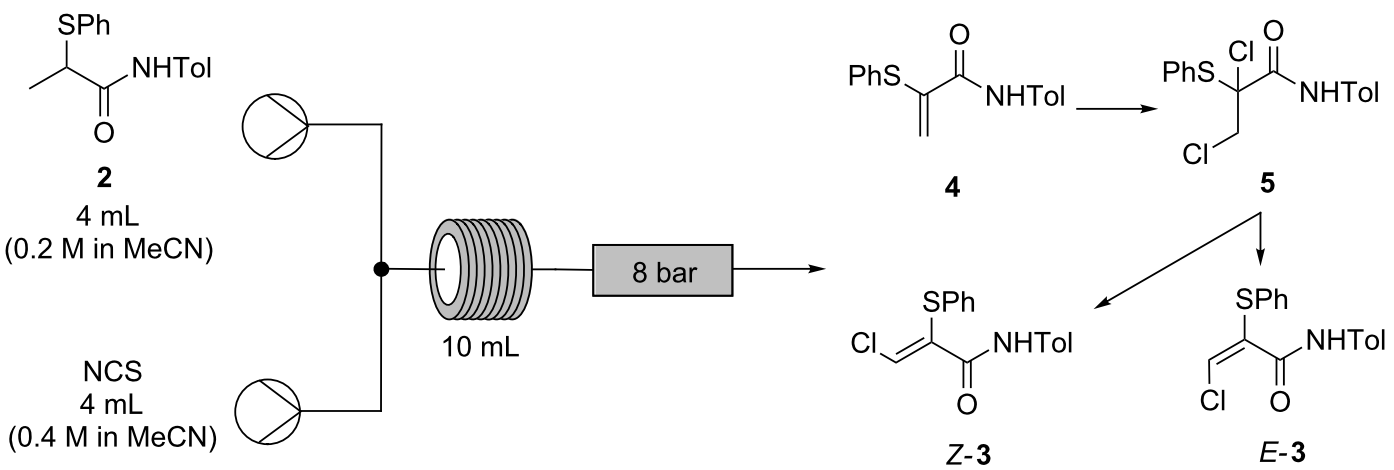

\begin{tabular}{|c|c|c|c|c|c|c|c|}
\hline \multirow[t]{2}{*}{ Entry } & \multirow{2}{*}{$\begin{array}{c}\text { Residence } \\
\text { time } \\
\text { (min) }\end{array}$} & \multirow{2}{*}{$\begin{array}{l}\text { Flow rate } \\
(\mathrm{mL} / \mathrm{min})\end{array}$} & \multirow{2}{*}{$\begin{array}{l}\text { Temp } \\
\left({ }^{\circ} \mathrm{C}\right)\end{array}$} & \multicolumn{4}{|c|}{ Product ratio ${ }^{b}$} \\
\hline & & & & $\begin{array}{c}Z-3 \\
(\%)^{C}\end{array}$ & $\begin{array}{c}E-3 \\
(\%)^{C}\end{array}$ & $\begin{array}{c}4 \\
(\%)^{\mathrm{C}}\end{array}$ & $\begin{array}{c}5 \\
(\%)^{\mathrm{C}}\end{array}$ \\
\hline 1 & 25 & 0.2 & 120 & 88.2 & 11.8 & 0.0 & 0.0 \\
\hline 2 & 15 & 0.3 & 120 & 87.6 & 12.4 & 0.0 & 0.0 \\
\hline 3 & 10 & 0.5 & 120 & 86.9 & 13.1 & 0.0 & 0.0 \\
\hline 4 & 5 & 1.0 & 120 & 85.5 & 14.5 & 0.0 & 0.0 \\
\hline 5 & 2 & 2.5 & 120 & 72.8 & 13.7 & 0.0 & 13.5 \\
\hline 6 & 2 & 2.5 & 80 & 4.9 & 2.3 & 0.0 & 92.7 \\
\hline 7 & 2 & 2.5 & 90 & 9.5 & 3.1 & 0.0 & 87.4 \\
\hline 8 & 2 & 2.5 & 100 & 17.3 & 4.4 & 0.0 & 78.3 \\
\hline 9 & 2 & 2.5 & 130 & 84.0 & 16.0 & 0.0 & 0.0 \\
\hline
\end{tabular}

a1 Equiv of a-thioamide 2 ( $4 \mathrm{~mL}$ of a $0.2 \mathrm{M}$ solution in MeCN) was reacted with 2 equiv of NCS ( $4 \mathrm{~mL}$ of a $0.4 \mathrm{M}$ solution in MeCN). bUnisolated components, not present after work-up were not included, but ranged from $5-10 \%$ by peak area. Molar ratio determined by HPLC analysis (peak area weighted for relative response factors of each component: see Supporting Information File 1) of samples taken directly from flow reactor as effluent solutions and diluted in MeCN prior to analysis. 
ingly low quantities of product $Z$-3. This finding is consistent with previous work showing that rapid heating resulted in a more efficient reaction cascade to the desired product Z-3, while slower heating leads to substantial quantities of reaction intermediates $\mathbf{4}$ and $\mathbf{5}$ as product impurities [3].

The stoichiometry of NCS used for the continuous process was also further optimized (Table 5). It was found that, at $130{ }^{\circ} \mathrm{C}$, 2 equivalents of NCS resulted in the lowest levels of the impurities arising from reaction intermediates and over-chlorination byproducts while also achieving one of the highest conversions to the desired $\alpha$-thio- $\beta$-chloroacrylamide $Z-3$ ( $82.9 \%$, entry 4 , Table 5).

This process was then operated on a $30 \mathrm{~g}$ scale (Scheme 8 ) to produce $19.3 \mathrm{~g}$ ( $57 \%$ yield, $>99 \%$ pure by HPLC analysis and ${ }^{1} \mathrm{H}$ NMR spectroscopy) of isolated $\alpha$-thio- $\beta$-chloroacrylamide $Z$-3 in less than 4 hours. The crude material was found to consist only of a mixture of the $Z$ - and $E$-isomers by ${ }^{1} \mathrm{H}$ NMR spectroscopy, with pure $Z-3$ selectively recovered after recrystallization, albeit with a loss of isolated yield from this process. This is the first instance in which multi-gram quantities of the product Z-3 have been isolated without the need for chromatography and on more than 3 times the scale which can be obtained in batch with the same reaction time [1]; the increase in quantity and the ease of purification compensates for the reduction in yield to $57 \%$. The material obtained by concentration of the liquors recovered from recrystallization were found to consist mainly of $Z-3$ and $E-3$ by ${ }^{1} \mathrm{H}$ NMR spectroscopy. Purification of this material by chromatography gave an additional $11 \%$ yield of pure $Z-3$ (3.7 g).

\section{Conclusion}

An efficient continuous flow methodology has been developed for the three-step synthesis of $\alpha$-thio- $\beta$-chloroacrylamide $Z$-3, which has overcome the challenges to scale-up posed by the

Table 5: Optimization of NCS stoichiometry for conversion of $\alpha$-thioamide 2 to $\alpha$-thio- $\beta$-chloroacrylamide Z-3 in continuous mode ${ }^{a}$.<smiles>CC(Sc1ccccc1)C(=O)N[Hg]Cl</smiles>

$4 \mathrm{~mL}$ $(0.2 \mathrm{M}$ in $\mathrm{MeCN})$ $2.5 \mathrm{~mL} / \mathrm{min}$

$4 \mathrm{~mL}$ (in $\mathrm{MeCN}$ ) $2.5 \mathrm{~mL} / \mathrm{min}$
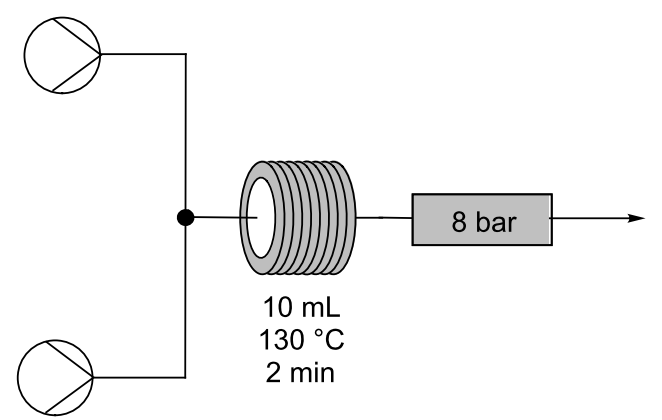<smiles>C=C(N[GaH2])C(=O)c1ccccc1</smiles>

4<smiles>O=C(N[Ga]Cl)C(=CCl)Sc1ccccc1</smiles>

Z-3

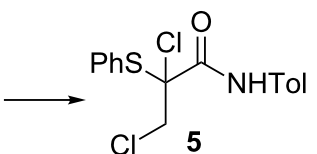<smiles>CC[SnH]/C(=C/Cl)C(=O)N[Ga]</smiles>

E-3<smiles>CC</smiles><smiles>O=C(N[GaH2])C(Cl)(c1ccccc1)C(Cl)Cl</smiles>

6

\begin{tabular}{ccccccc}
\hline Entry & $\begin{array}{c}\text { NCS } \\
\text { equiv }\end{array}$ & $\begin{array}{c}Z-3 \\
(\%)^{\mathrm{c}}\end{array}$ & $\begin{array}{c}E-3 \\
(\%)^{\mathrm{c}}\end{array}$ & $\begin{array}{c}\text { Product ratio }^{\mathrm{b}} \\
(\%)^{\mathrm{c}}\end{array}$ & $\begin{array}{c}\mathbf{5} \\
(\%)^{\mathrm{c}}\end{array}$ & $\begin{array}{c}\mathbf{6} \\
(\%)^{\mathrm{c}}\end{array}$ \\
\hline 1 & 1.7 & 68.8 & 13.1 & 18.1 & 0.0 & 0.0 \\
2 & 1.9 & 73.8 & 14.1 & 12.1 & 0.0 & 0.0 \\
3 & 1.95 & 76.5 & 14.8 & 8.6 & 0.0 & 0.0 \\
4 & 2 & 82.9 & 15.8 & 1.3 & 0.0 & 0.0 \\
5 & 2.05 & 81.6 & 15.9 & 1.4 & 0.0 & 1.1 \\
6 & 2.1 & 81.3 & 15.3 & 1.7 & 0.0 & 1.7 \\
7 & 2.2 & 69.4 & 11.9 & 0.0 & 0.0 & 18.7 \\
\hline
\end{tabular}

a1 Equiv of $\alpha$-thioamide 2 ( $4 \mathrm{~mL}$ of $0.2 \mathrm{M}$ solution in MeCN) was reacted with NCS ( $4 \mathrm{~mL}$ of solution in MeCN) at $130{ }^{\circ} \mathrm{C}$ for 2 min, using a flow rate of $2.5 \mathrm{~mL} / \mathrm{min}$. bMolar ratio determined by HPLC analysis (peak area weighted for relative response factors of each component: see Supporting Information File 1) of samples taken directly from flow reactor as effluent solutions and diluted in MeCN prior to analysis. 'Unisolated components, not present after work-up were not included, but ranged from $2-14 \%$ by peak area. 


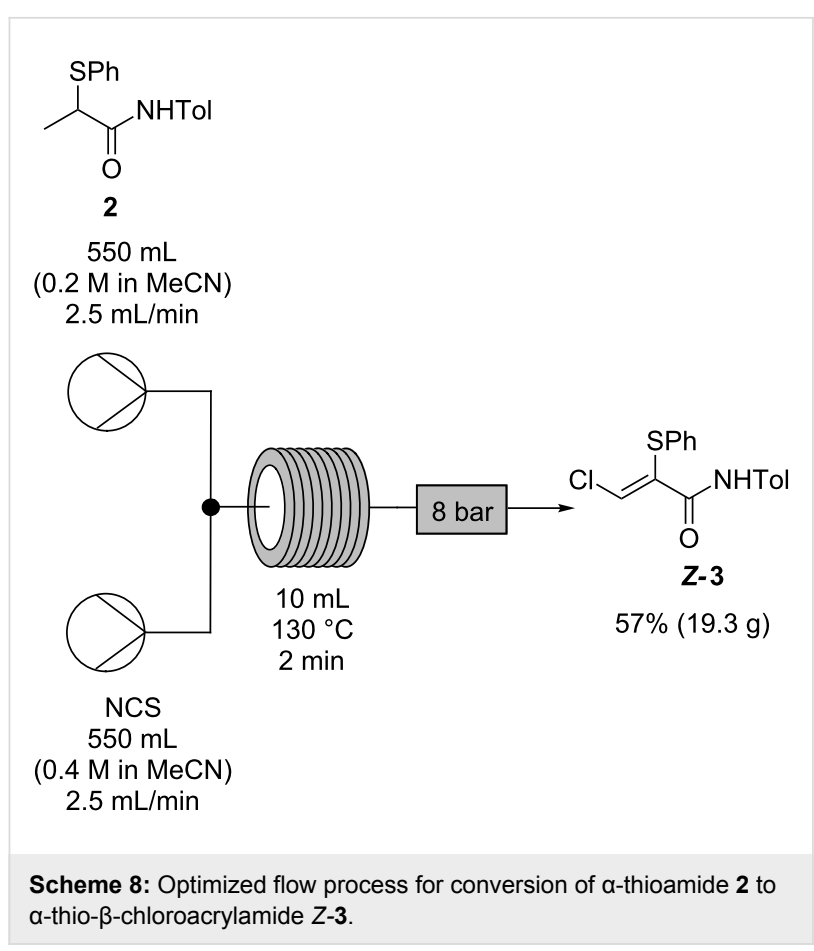

conventional batch preparation. This approach has yielded improvements in process safety, significantly reduced reaction times and increased product purity, obviating the need for chromatography. One process, preparation of $\alpha$-thioamide 2 ultimately proved most efficient in batch, though the investigations performed in flow were critical to achieving the optimization. The easy access to synthetically useful amounts, afforded by a transfer to continuous processing, is expected to significantly increase the attractiveness of harnessing the enormous potential utility of $\alpha$-thio- $\beta$-chloroacrylamides on a more widespread basis. Perhaps the most powerful outcome is the ability to control the $\beta$-chloroacrylamide cascade through continuous processing, leading to selective recovery of individual components of the reaction.

\section{Supporting Information}

\section{Supporting Information File 1}

General information, experimental procedures, analytical data and copies of NMR spectra of all compounds.

[http://www.beilstein-journals.org/bjoc/content/ supplementary/1860-5397-12-246-S1.pdf]

\section{Acknowledgements}

This work was undertaken as part of the Synthesis and Solid State Pharmaceutical Centre supported by the Science Foundation Ireland (grant: SFI SSPC2 12/RC/2275). The authors would like acknowledge the contribution of Janssen Pharma- ceutical, for the kind loan of one of the flow chemistry reactors used in this work.

\section{References}

1. Murphy, M.; Lynch, D.; Schaeffer, M.; Kissane, M.; Chopra, J.; O'Brien, E.; Ford, A.; Ferguson, G.; Maguire, A. R. Org. Biomol. Chem. 2007, 5, 1228-1241. doi:10.1039/B618540A

2. Maguire, A. R.; Murphy, M. E.; Schaeffer, M.; Ferguson, G. Tetrahedron Lett. 1995, 36, 467-470. doi:10.1016/0040-4039(94)02288-M

3. Kissane, M.; Maguire, A. R. Synlett 2011, 1212-1232. doi:10.1055/s-0030-1260559

4. Kissane, M.; Murphy, M.; O’Brien, E.; Chopra, J.; Murphy, L.; Collins, S. G.; Lawrence, S. E.; Maguire, A. R. Org. Biomol. Chem. 2011, 9, 2452-2472. doi:10.1039/c0ob00805b

5. Kissane, M.; Lynch, D.; Chopra, J.; Lawrence, S. E.; Maguire, A. R. Org. Biomol. Chem. 2010, 8, 5602-5613. doi:10.1039/c0ob00368a

6. Kissane, M.; Murphy, M.; Lynch, D.; Ford, A.; Maguire, A. R. Tetrahedron 2008, 64, 7639-7649. doi:10.1016/j.tet.2008.05.026

7. Kissane, M.; Lawrence, S. E.; Maguire, A. R. Org. Biomol. Chem. 2010, 8, 2735-2748. doi:10.1039/c002479a

8. Kissane, M.; Maguire, A. R. Chem. Soc. Rev. 2010, 39, 845-883. doi:10.1039/B909358N

9. Kissane, M.; Lawrence, S. E.; Maguire, A. R. Tetrahedron 2010, 66, 4564-4572. doi:10.1016/j.tet.2010.04.057

10. Kissane, M.; Lynch, D.; Chopra, J.; Lawrence, S. E.; Maguire, A. R. Tetrahedron: Asymmetry 2008, 19, 1256-1273. doi:10.1016/j.tetasy.2008.04.033

11. Kissane, M.; Lawrence, S. E.; Maguire, A. R. Tetrahedron: Asymmetry 2010, 21, 871-884. doi:10.1016/j.tetasy.2010.05.004

12. Kissane, M.; Murphy, M.; Lawrence, S. E.; Maguire, A. R. Tetrahedron: Asymmetry 2010, 21, 2550-2558. doi:10.1016/j.tetasy.2010.10.007

13. Tietze, L. F. Chem. Rev. 1996, 96, 115-136. doi:10.1021/cr950027e 14. Wegner, J.; Ceylan, S.; Kirschning, A. Adv. Synth. Catal. 2012, 354, 17-57. doi:10.1002/adsc.201100584

15. Wirth, T., Ed. Microreactors in Organic Chemistry and Catalysis; Wiley-VCH Verlag GmbH \& Co. KGaA: Weinheim, Germany, 2013.

16. Baxendale, I. R.; Brocken, L.; Mallia, C. J. Green Process. Synth. 2013, 2, 211-230. doi:10.1515/gps-2013-0029

17. Pastre, J. C.; Browne, D. L.; Ley, S. V. Chem. Soc. Rev. 2013, 42, 8849-8869. doi:10.1039/c3cs60246j

18. Webb, D.; Jamison, T. F. Chem. Sci. 2010, 1, 675-680. doi:10.1039/c0sc00381f

19. McQuade, D. T.; Seeberger, P. H. J. Org. Chem. 2013, 78, 6384-6389. doi:10.1021/jo400583m

20. Hartman, R. L.; McMullen, J. P.; Jensen, K. F. Angew. Chem., Int. Ed. 2011, 50, 7502-7519. doi:10.1002/anie.201004637

21. Gutmann, B.; Cantillo, D.; Kappe, C. O. Angew. Chem., Int. Ed. 2015, 54, 6688-6728. doi:10.1002/anie.201409318

22. Movsisyan, M.; Delbeke, E. I. P.; Berton, J. K. E. T.; Battilocchio, C.; Ley, S. V.; Stevens, C. V. Chem. Soc. Rev. 2016, 45, 4892-4928. doi:10.1039/C5CS00902B

23. Deadman, B. J.; Collins, S. G.; Maguire, A. R. Chem. - Eur. J. 2015, 21, 2298-2308. doi:10.1002/chem.201404348

24. Müller, S. T. R.; Wirth, T. ChemSusChem 2015, 8, 245-250. doi:10.1002/cssc.201402874 
25. Deadman, B. J.; O’Mahony, R. M.; Lynch, D.; Crowley, D. C.; Collins, S. G.; Maguire, A. R. Org. Biomol. Chem. 2016, 14, 3423-3431. doi:10.1039/C6OB00246C

26. Kopach, M. E.; Roberts, D. J.; Johnson, M. D.; McClary Groh, J.; Adler, J. J.; Schafer, J. P.; Kobierski, M. E.; Trankle, W. G. Green Chem. 2012, 14, 1524-1536. doi:10.1039/c2gc35050e 27. Prat, D.; Wells, A.; Hayler, J.; Sneddon, H.; McElroy, C. R.; Abou-Shehada, S.; Dunn, P. J. Green Chem. 2016, 18, 288-296. doi:10.1039/C5GC01008J

28. Pinho, S. P.; Macedo, E. A. J. Chem. Eng. Data 2005, 50, 29-32. doi:10.1021/je049922y

29. Foley, D. A.; Doecke, C. W.; Buser, J. Y.; Merritt, J. M.; Murphy, L.; Kissane, M.; Collins, S. G.; Maguire, A. R.; Kaerner, A. J. Org. Chem. 2011, 76, 9630-9640. doi:10.1021/jo201212p

\section{License and Terms}

This is an Open Access article under the terms of the Creative Commons Attribution License

(http://creativecommons.org/licenses/by/4.0), which permits unrestricted use, distribution, and reproduction in any medium, provided the original work is properly cited.

The license is subject to the Beilstein Journal of Organic Chemistry terms and conditions:

(http://www.beilstein-journals.org/bjoc)

The definitive version of this article is the electronic one which can be found at: doi:10.3762/bjoc. 12.246 